\title{
Protocol
}

\section{Immunohistochemical identification of multipotent adult progenitor cells from human bone marrow after transplantation into the rat brain}

\author{
Li-Ru Zhao ${ }^{a}$, Wei-Ming Duan ${ }^{\mathrm{a}}$, Morayma Reyes ${ }^{\mathrm{b}, \mathrm{c}}$, Catherine M. Verfaillie ${ }^{\mathrm{b}, \mathrm{c}}$, \\ Walter C. Low ${ }^{\mathrm{a}, \mathrm{d}, *}$ \\ ${ }^{a}$ Department of Neurosurgery, University of Minnesota Medical School, Lions Research Building, Room 421, 2001 Sixth Street S.E., Minneapolis, \\ MN 55455, USA \\ ${ }^{\mathrm{b}}$ Department of Internal Medicine, University of Minnesota, Minneapolis, MN 55455, USA \\ ${ }^{\mathrm{c}}$ Stem Cell Institute, University of Minnesota, Minneapolis, MN 55455, USA \\ ${ }^{\mathrm{d}}$ Graduate Program in Neuroscience, University of Minnesota, Minneapolis, MN 55455, USA
}

Accepted 13 December 2002

\begin{abstract}
In the immunohistochemical analysis of the brain, tissue preparation and fixation are critical steps. During our studies of transplanting human bone marrow multipotent adult progenitor cells (hMAPCs) into the rat brain, we noticed that various methods of brain tissue preparation and fixation differentially influenced antigenic preservation in the transplants and in the host brain. Here, we report a simple, effective and reproducible method of tissue preparation and fixation that results in the immunohistochemical labeling of transplanted and host cells.
\end{abstract}

(C) 2003 Elsevier Science B.V. All rights reserved.

Theme: Development and regeneration

Topic: Transplantation

Keywords: Fast frozen; Ethanol; Formaldehyde; Bone marrow stem cell; Transplantation

\section{Type of research}

Bone marrow mesenchymal stem cells have been shown to exhibit tremendous plasticity in cellular phenotypes. They cannot only differentiate into cells of a mesodermal lineage $[3,9,19,26,34]$ but also adopt endodermal lineages $[25,27]$ and an ectodermal fate giving rise to neurons and astrocytes $[6,10,16,19,21,31,36]$. Recently, we have reported that transplanted human multipotent adult progenitor cells (hMAPCs) from bone marrow survive and express neural tissue antigens, and improve functional outcomes after grafting into the ischemic brain of rats [37]. We have also observed that hMAPCs adopt neural fates when they are implanted into the brain of neonatal rats

\footnotetext{
*Corresponding author. Tel.: +1-612-626-9200; fax: +1-612-6269201.

E-mail addresses: lowwalt@tc.umn.edu (W.C. Low), http:/ /www.neuro.umn.edu/ (W.C. Low).
}

(unpublished data). During these studies, however, we found that the routine procedure of using formaldehyde perfusion for immunohistochemistry to identify grafted human bone marrow mesenchymal stem cells in the brain was not adequate. We have postulated that the antigen epitopes of hMAPCs may be vulnerable to formaldehyde perfusion. Therefore, we established the method of fast freezing of fresh brain tissue in powdered dry ice, cutting with a cryostat into thin sections and then briefly fixing with $4 \%$ formaldehyde. This is a simple, effective and reproducible method of immunohistochemical detection of transplanted hMAPCs in rat brain. Here, we report this method in detail.

\section{Time required}

- Focal brain ischemia—right middle cerebral artery ligation: $15-20 \mathrm{~min} / \mathrm{rat}$. 
- Transplantation of hMAPCs-injection of hMAPCs: 6-8 $\mathrm{min} / \mathrm{site}$.

- Tissue preparation-animal decapitation and brain removal and freeze: $1-2 \mathrm{~min} / \mathrm{rat}$.

- Brain sectioning - cutting brain with cryostat: $30 \mathrm{~min} /$ rat brain.

- Immunohistochemistry.

- Single staining: 2 days.

- Double staining: 3 days.

\section{Materials}

\subsection{Animals}

The Institutional Animal Care and Use Committee at the University of Minnesota approved the experimental protocols. The experiment was conducted under the auspices of Research Animal Resources, a facility approved by the American Association for the Accreditation of Laboratory Animal Care. Adult spontaneously hypertensive rats (SHR), weighing 250-300 g (Charles River, Wilmington, MA, USA), and Sprague-Dawley (SD, postnatal day 3, Charles River) were used for this study. The animals were housed under conditions of $12 \mathrm{~h}$ light: $12 \mathrm{~h}$ darkness cycle, $23 \pm 1{ }^{\circ} \mathrm{C}, 60 \pm 10 \%$ humidity, and allowed free access to water and food throughout the experiment.

\subsection{Chemicals and reagents}

- Anesthetics.

- Methohexital sodium (Jones Pharma, St. Louis, MO, USA).

- Equithesin $\left[\mathrm{MgSO}_{4} \cdot 7 \mathrm{H}_{2} \mathrm{O}\right.$, chloral hydrate, 1,2propandiol (Sigma, St. Louis, MO, USA), pentobarbital sodium (Abbott Laboratories, North Chicago, IL, USA)].

- Chloral hydrate (Sigma).

- Cyclosporin A (Novartis, New York, NY, USA).

- ABC kit (Vector Labs, Burlingame, CA, USA).

- Tris buffered saline (TBS) (Sigma).

- Sodium chloride (Sigma).

- Bovine serum albumin (BSA) (Sigma).

- Triton X-100 (Sigma).

- 3,3-Diaminobenzidine tetrahydrochloride

$(\mathrm{DAB})$ (Sigma).

- Hematoxylin (Sigma).

- Normal serum: horse or goat (Vector Labs).

- Primary mouse monoclonal antibodies.

- Neuronal nuclei (NeuN) (Chemicon, Temecula, CA, USA).

- Neurofilament 160 (NF160) (Sigma).

- Neurofilament 200 (NF200) (Sigma).

- Glial fibrillary acidic protein (GFAP) (Sigma).

- Myelin/oligodendrocyte specific protein (Chemicon).
- Human nuclei (Chemicon).

- Primary polyclonal antibodies.

- Rabbit anti-GFAP (Sigma).

- Rabbit anti-NF200 (Sigma).

- Rabbit anti-galactocerebroside (GalC) (Sigma).

- Secondary antibodies.

- Biotinylated secondary antibodies (Vector Labs).

- Cy2 conjugated goat anti-mouse IgG (Jackson ImmunoResearch, West Grove, PA, USA).

- Cy3 conjugated goat anti-rabbit IgG (Jackson ImmunoResearch).

- Mounting media.

- DPX (Sigma).

- Glycerol containing $n$-propyl gallate (Sigma).

\subsection{Special equipment}

- Surgery microscopy (Nikon, Tokyo, Japan).

- Stereological frame (Kopf Instruments, Tujunga, CA, USA).

- 10 ul Hamilton microsyringe (Hamilton, Reno, NV, USA).

- Cryostat (Leica, Nussloch, Germany).

\section{Detailed procedure}

\subsection{Surgery}

Cortical brain ischemia in SHR was produced by permanently ligating the middle cerebral artery (MCA) distal to the striatal branch as described elsewhere [7]. One week after brain ischemia, the rats were anesthetized with equithesin ( $3 \mathrm{ml} / \mathrm{kg}$, i.p.). Three microlitres of human bone marrow stem cells $(25,000$ cells $/ \mu 1)$ were transplanted into the cortex surrounding the infarction. Three sites were selected for transplantation at the following coordinates: (1) $1.0 \mathrm{~mm}$ rostral to the bregma, $2.0 \mathrm{~mm}$ lateral to the midline, $1.2 \mathrm{~mm}$ ventral to the dura; (2) $3.0 \mathrm{~mm}$ caudal to the bregma, $1.5 \mathrm{~mm}$ lateral to the midline, $1.2 \mathrm{~mm}$ ventral to the dura; (3) $6.0 \mathrm{~mm}$ caudal to the bregma, $2.0 \mathrm{~mm}$ lateral to the midline, $1.2 \mathrm{~mm}$ ventral to the dura. The tooth-bar was set at zero. Cyclosporin A was given daily (10 $\mathrm{mg} / \mathrm{kg}$, i.p.). In another study, $2 \mu \mathrm{l}$ of human bone marrow stem cells ( 7000 cells $/ \mu 1)$ were bilaterally injected into the lateral ventricles of neonatal rats (postnatal day 3, $\mathrm{SD})$. The injection sites were $0.6 \mathrm{~mm}$ caudal to the bregma, $0.8 \mathrm{~mm}$ lateral to the midline and $2.1 \mathrm{~mm}$ ventral to the dura. The tooth-bar was set at one.

\subsection{Tissue preparation}

The rats were anaesthetized with chloral hydrate (350 $\mathrm{mg} / \mathrm{kg}$, i.p.) and decapitated 2 weeks (for ischemic SHR) or 4 weeks (for neonatal SD) after transplantation. The 
brains were then quickly removed, immediately frozen in powdered dry ice, and individually stored in plastic bags at $-80^{\circ} \mathrm{C}$. Before sectioning, the brains were placed at $-20{ }^{\circ} \mathrm{C}$ overnight. Coronal cryostat sections, $10 \mu \mathrm{m}$ thick, were cut and mounted on superfrost plus microscope slides (Fisher Scientific, Hanover Park, IL, USA) and then stored at $-80{ }^{\circ} \mathrm{C}$.

\subsection{Tissue fixation}

The sections were stored at $-20{ }^{\circ} \mathrm{C}$ for $1-2 \mathrm{~h}$, air-dried at room temperature for 30-60 min, and then fixed with freshly prepared $4 \%$ formaldehyde in Tris buffered saline (TBS) $(0.05 \mathrm{M}, \mathrm{pH} 7.6)$ for $15 \mathrm{~min}$. For an alternative fixative, the sections were fixed with $1 \%$ formaldehyde in $95 \%$ ethanol for $15 \mathrm{~min}$.

\subsection{Immunohistochemistry}

After rinsing in TBS, the sections were exposed to $0.3 \%$ $\mathrm{H}_{2} \mathrm{O}_{2}$ for $30 \mathrm{~min}$ to quench endogenous peroxidase activities. Before incubation of primary antibodies, nonspecific binding was blocked with normal serum (1:10, diluted with $0.1 \% \mathrm{BSA}+0.25 \%$ Triton $\mathrm{X}-100$ ) from the species in which the secondary antibody was raised. The duration of the blocking was $30 \mathrm{~min}$. The sections were then incubated with the primary antibodies diluted by $0.1 \%$ $\mathrm{BSA}+0.25 \%$ Triton $\mathrm{X}-100$ overnight at $4{ }^{\circ} \mathrm{C}$. The primary antibodies used for this study were mouse monoclonal antibodies: neuronal nuclei $(1: 100)$, neurofilament 160 (1:100), neurofilament 200 (1:400), glial fibrillary acidic protein (1:500) and myelin/oligodendrocyte specific protein (1:1000). Rabbit anti-galactocerebroside (1:50), a polyclonal antibody, was employed as well. After rinsing in TBS, the sections were incubated with biotinylated secondary antibodies diluted with $0.1 \% \quad \mathrm{BSA}+0.25 \%$ Triton X-100 for $1 \mathrm{~h}$ at room temperature and the reaction products were visualized by the avidin-biotin-peroxidase complex method (ABC kit) using 3,3-diaminobenzidine tetrahydrochloride as the chromogen. The sections were then counterstained with hematoxylin, dehydrated and mounted with DPX. The adjacent sections served as negative controls. All the procedures for negative controls were processed in the same manner except the primary antibodies were omitted.

For immunofluorescent double staining, nonspecific binding was blocked by normal goat serum. The sections were incubated overnight at $4{ }^{\circ} \mathrm{C}$ with the first primary antibodies: mouse anti-human nuclei (1:20), or mouse anti-NeuN (1:100). After rinsing in TBS, the sections were exposed to Cy2 conjugated goat anti-mouse IgG (1:100), the secondary antibody, for $2 \mathrm{~h}$ at room temperature in the dark. After blocking nonspecific binding, the sections were then incubated with other primary antibodies: rabbit antiGFAP (1:500) or rabbit anti-NF200 (1:200) at $4{ }^{\circ} \mathrm{C}$ overnight. Finally, the sections were incubated with $\mathrm{Cy} 3$ conjugated goat anti-rabbit $\operatorname{IgG}(1: 400)$ at room temperature for $2 \mathrm{~h}$ in the dark, rinsed with TBS and mounted with glycerol containing $n$-propyl gallate. The adjacent sections were used as negative controls. All the procedures for negative controls were processed in the same manner except the primary antibodies were omitted. Immunoperoxidase reactivity was assessed with light microscopy, and fluorescent staining was evaluated using a fluorescence microscope (Nikon).

\section{Results}

\subsection{Immunoperoxidase staining}

In fixing the sections with $1 \%$ formaldehyde in $95 \%$ ethanol, positive immunoreactivity (e.g. NF-200, GFAP) was only observed in the transplanted human bone marrow stem cells (Fig. 1A, NF-200; E, GFAP). Antigenicity was not well preserved in host brain tissue (Fig. 1C, NF-200; G, GFAP).

When the cryostat sections were fixed with $4 \%$ buffered formaldehyde, antigenicity was well preserved in both the transplanted hMAPCs and in the host rat brain tissue. Histological details were also better preserved than with fixation using 1\% FA in ethanol. Positive immunoreactions of neurofilament-200 and GFAP were detected in both grafted human bone marrow stem cells (Fig. 1B: NF-200, F: GFAP) and host brain tissue (Fig. 1D: NF-200, H: GFAP). In a fixation time test, 3-10-min fixations were better than $1 \mathrm{~min}$. The 15 -min fixation was superior to the fixations of 3-10 $\mathrm{min}$ and $1 \mathrm{~min}$.

Several antibodies were evaluated in the present study (Table 1). Those antibodies included NeuN, NF-160, NF200, GFAP, GalC and myelin (oligodendrocyte specific protein). In the fixation protocol of $1 \% \mathrm{FA}$ in $95 \%$ ethanol only NeuN exhibited a weak immunoreactivity in the host brain. The rest of the antibodies showed no positive immunoreactivity to the host epitopes. However, the antigenicity was preserved in grafted hMAPCs by using $1 \%$ FA with alcohol fixation since all selected neural cell markers showed positive immunoreactivities. When the sections were fixed with $4 \% \mathrm{FA}$, the antigenicity was preserved in both host brain tissue and grafts.

\subsection{Immunofluorescence staining}

To determine the effects of fast freezing, cryostat sections with $4 \%$ formaldehyde fixation on immunofluorescent 3-day double staining, sections were double labeled with anti-human nuclei+anti-GFAP for grafts, anti-NeuN+anti-NF-200 for host brain tissue. We noticed that transplanted hMAPCs were immunopositive to both antibodies of human nuclei (green) and GFAP (red). NeuN 


\section{$1 \% \mathrm{FA}+95 \%$ ethanol $\quad 4 \% \mathrm{FA}$}

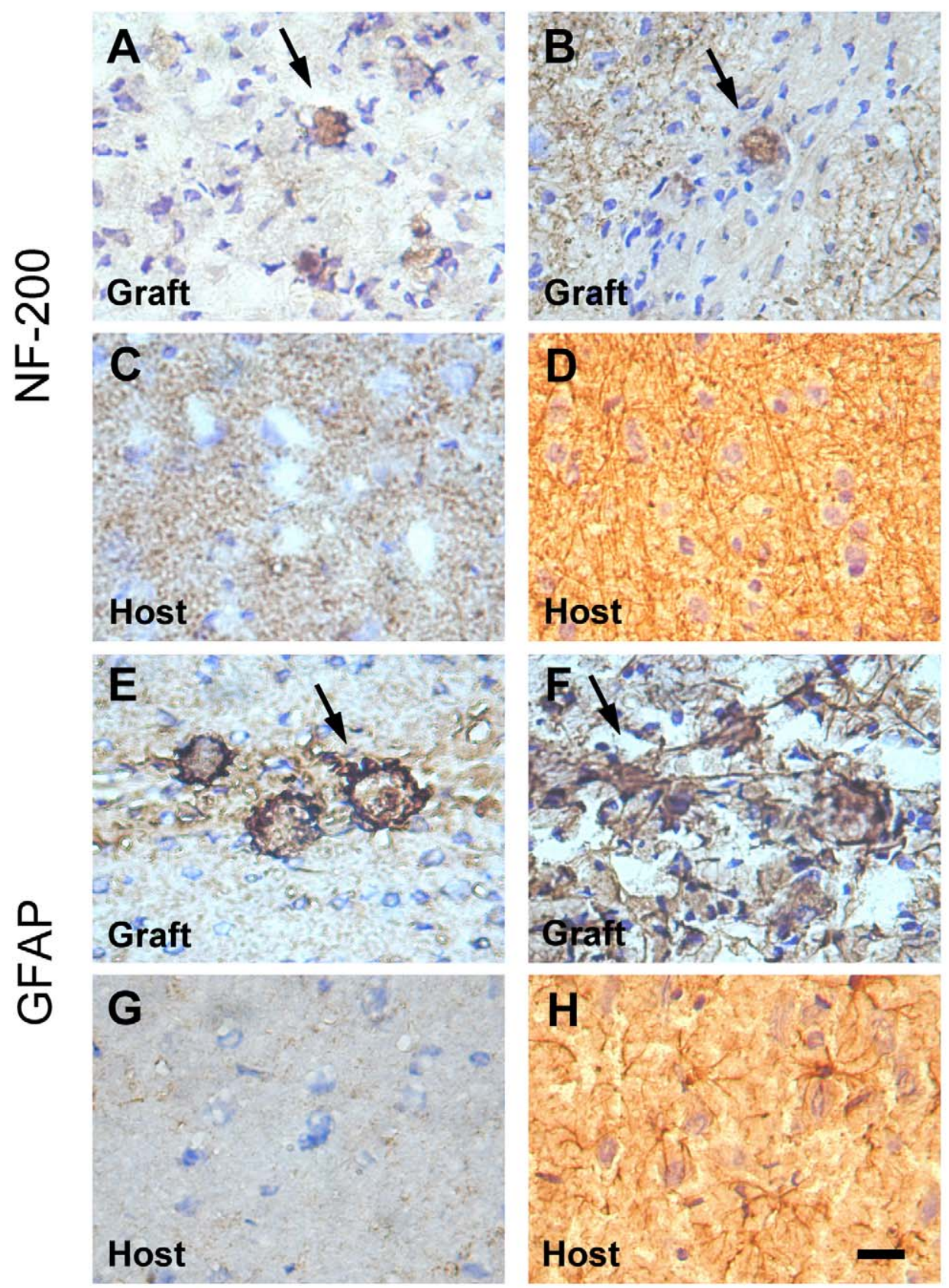

Fig. 1. Immunoperoxidase staining. Cryostat sections from rats that received intracerebral human bone marrow stem cell transplants $(2$ weeks after grafting) were fixed with $1 \%$ formaldehyde in $95 \%$ ethanol (A, C, E and G), or fixed with $4 \%$ formaldehyde in TBS (B, D, F and $\mathrm{H}$ ) for 15 min in room temperature. (A-D) Anti-NF-200. (E-H) Anti-GFAP. Photomicrographs in panels A, B, E and F are taken from the transplant site; panels C, D, G and H are taken from the host brain. For the sections fixed with $1 \%$ FA in $95 \%$ ethanol, immunoreactivity was only observed in grafted human bone marrow mesenchymal stem cells (A, NF- $200^{+}$grafted cells in the site of transplantation; E, GFAP ${ }^{+}$grafted cells in the site of transplantation) but the immunoreactivity was absent in the host brain tissue (C, negative immunoreactivity for NF-200 in host cortex; G, negative immunoreactivity for GFAP in host hippocampus). For the sections fixed with $4 \%$ formaldehyde in TBS, positive immunoreactivities were identified in both grafts (B, NF-200 ${ }^{+}$cell in the site of transplantation; F, GFAP ${ }^{+}$cells in the site of transplantation) and the host brain tissue (D, immunopositive staining for NF-200 in host cortex; H, $\mathrm{GFAP}^{+}$astrocytes in hippocampus). Note that sections fixed with 4\% FA exhibit better histological structures (neuronal fibers and the processes of astrocytes) than those fixed with $1 \%$ FA in $95 \%$ ethanol. Arrows indicate grafted human bone marrow mesenchymal stem cells. Bar $=20 \mu \mathrm{m}$.

(green)-NF200 (red) double stained neurons were detected in the host cortex (Fig. 2). The staining was successful with low background and without tissue loss. These data indicate that the $4 \%$ formaldehyde fixation protocol for cryostat sections is adequate for immunofluorescent double staining. 
Table 1

Immunoreactivity in host and graft influenced by the fixations of $1 \%$ FA in $95 \%$ ethanol and $4 \%$ FA

\begin{tabular}{|c|c|c|c|c|}
\hline & \multicolumn{2}{|c|}{$1 \% \mathrm{FA}$ in $95 \%$ ethanol } & \multicolumn{2}{|c|}{$4 \% \mathrm{FA}$} \\
\hline & Host & Graft & Host & Graft \\
\hline NeuN & \pm & + & + & + \\
\hline NF160 & - & + & + & + \\
\hline NF200 & - & + & + & + \\
\hline GFAP & - & + & + & + \\
\hline GalC & - & + & + & + \\
\hline Myelin & - & + & + & + \\
\hline
\end{tabular}

The antibodies used in this study are immunoreactive to both human and rat tissue.

\section{Discussion}

The main cause of the loss of antigenicity is tissue preparation and fixation $[2,32,35]$. The perfusion of aldehyde-based fixatives, especially formaldehyde, is routinely used for immunohistochemical tissue preparation and fixation. This technique produces good morphology, while the immunoreactivity is sometimes limited, especially for monoclonal antibodies [2,20,23,35]. It has been reported that formaldehyde perturbs the three-dimensional structure of protein and masks antigenic epitopes especially when the fixation period is prolonged [20,35]. In the beginning of the series of studies transplanting hMAPCs into the brain in our laboratory, the rats were perfused with $4 \%$ buffered formaldehyde. However, the antigenicity of grafted hMAPCs was not preserved. We have hypothesized that the antigenic epitopes of the grafted hMAPCs might be vulnerable to formaldehyde perfusion.

The techniques of protease digestion and microwave heating have been reported to be effective for retrieving antigens from formaldehyde fixation [8,14,15,33]. However, both proteolytic digestion and heating are nonspecific, which may lead to false negative or false positive results $[1,35]$. In our study we used a simple, effective and reproducible method of brain preparation and fixation for immunohistochemistry in both transplanted hMAPCs and the host brain that does not require protease digestion or microwave heating. In this method the brains were frozen rapidly in powdered dry ice and cut into thin sections (10 $\mu \mathrm{m})$ with a cryostat. The sections were then fixed with $4 \%$ buffered formaldehyde for a brief period of time (15 min). Under light microscopy, the sections processed by this protocol exhibited good immunoreactivity and morphological preservation.

\subsection{Trouble-shooting}

\subsubsection{Tissue preparation}

The ideal tissue preparation for histological and immunohistological studies is to immobilize the tissue in a manner that is as life-like as possible [11]. Rapid freezing of tissue is an approach that closely meets this criterion. In the present study, the brains were quickly removed after
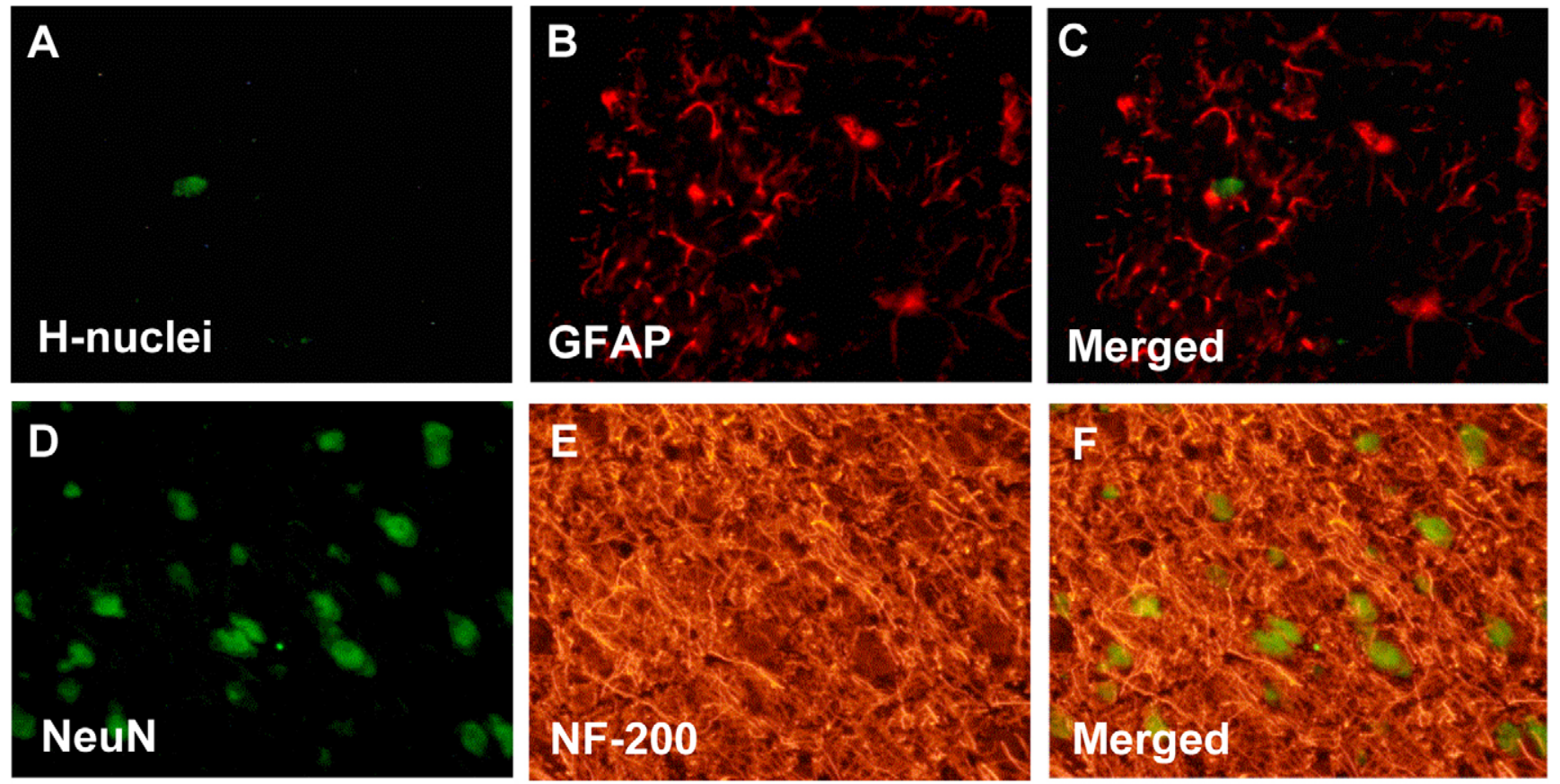

Fig. 2. Immunofluorescent staining. Immunofluorescent positive cells were detected in both graft cells and host brain tissue. (A-C) Human nuclei-GFAP double labeled grafted cell in the striatum of a neonatal rat received human bone marrow mesenchymal stem cell transplantation 1 month post-grafting (A, human nuclei ${ }^{+}$cell visualized by $\mathrm{Cy} 2$ conjugated secondary antibody; $\mathrm{B}, \mathrm{GFAP}^{+}$astrocytes visualized by $\mathrm{Cy} 3$ conjugated secondary antibody; $\mathrm{C}, \mathrm{A}$ and $\mathrm{B}$ merged panel). (D-F) NeuN-NF-200 double staining in host cortex (D, NeuN ${ }^{+}$staining for nuclei of neurons visualized by Cy 2 conjugated secondary antibody; E, NF-200 ${ }^{+}$staining visualized by Cy3 conjugated secondary antibody; F, merged with D and E). Magnification: $\times 40$. 
decapitation, then immediately frozen in powdered dry ice, and stored at $-80^{\circ} \mathrm{C}$. Therefore, the biological reactions were quickly arrested and most of the molecules were immobilized in cells, which closely approximates the live state [24].

Moreover, most of the general protease inhibitors are active at low temperature, so tissue proteins can be preserved under low temperature storage. It has been shown that brain tissue can be stored at $-70{ }^{\circ} \mathrm{C}$ for more than 3 years without change in its mRNA signal and antigenicity $[17,22]$. The method of fast freezing rat brains in powdered dry ice has been successfully used for determination of neurotrophic factor mRNA expression $[18,38]$. As shown in the present study, the antigenicity of the brain was well preserved by rapid freezing of the tissue.

In order to properly use this method, we suggest that first, after decapitating, the brain should be removed and frozen as soon as possible. The whole procedure should be within 1-2 min. Secondly, freezing the brain in powdered dry ice is important. Freezing brain tissue in liquid nitrogen directly is not recommended, because the brain tissue is easily shattered. Organic solvents, such as ethanol, methanol and isopentane should not be used. They may influence the optimal result of immunohistochemistry for brain tissue sections (discussed below). Finally, always keep the brain tissue and sections in the frozen state before staining.

\subsubsection{Fixatives}

The optimal fixative should preserve antigenicity and also provide good morphology. The fixatives are classified into two groups: coagulants such as alcohols and acetone, and cross-linking agents like glutaraldehyde and formaldehyde. Generally, coagulants preserve antigenicity but cannot render tissue with fine cellular structure, whereas cross-linking agents preserve morphology very well but with low antigenicity $[2,11]$. In the present study, we tried cryostat sections that were fixed in $1 \%$ formaldehyde (FA) with $95 \%$ ethanol. We postulated that this combination might result in a better compromise for both antigenicity and morphology. However, the results were unexpected. The positive immunoreactions were only observed in transplanted bone marrow stem cells, and were hard to detect in host brain tissue. In order to determine if this result was due to insufficient fixation, the sections were fixed in ethanol first for $15 \mathrm{~min}$ and then followed by a 15 -min- $4 \%$ formaldehyde fixation. Surprisingly, the results were exactly the same as $1 \%$ FA in $95 \%$ ethanol (data not shown). To determine whether the high concentration of ethanol reduced antigenicity of brain tissue, the sections were then fixed with $1 \%$ FA but in different concentrations of ethanol $(70 \%, 50 \%$ and $30 \%)$. The results showed that high concentrations of alcohol reduced antigenicity. In addition, the antigenicity and morphology were not well preserved in lower concentrations of alcohol. These data indicated that ethanol, especially high concentrations of ethanol, interfered with antigenicity and morphological preservation of brain tissue. Riederer et al. [29] has reported that most microtubule proteins are soluble in alcohol-fixed cat brain tissue. Brain tissue is rich in lipids [13], and ethanol dissolves and extracts lipids in both the membranes and cytoplasm [20]. In contrast, formaldehyde is an adequate fixative for lipids [5]. Therefore, 4\% buffered formaldehyde alone for fixation was tested. Using this method, the immunoreactivity was observed in both donor tissue (hMAPCs) and host rat brain tissue. In addition to the preservation of antigenicity with this fixation method, the sections also displayed good morphological preservation. Formaldehyde has been shown to penetrate quickly but fixes the tissue slowly $[4,12]$. In order to determine if a 15 -min fixation for $4 \%$ formaldehyde was sufficient, the sections were fixed in $4 \%$ FA with Triton X-100 for $10 \mathrm{~min}, 4 \%$ FA $10 \mathrm{~min}$, then immersed in cold acetone for $10 \mathrm{~min}$. The results did not differ from the 4\% FA fixation alone (data not shown). Moreover, it has been reported that formaldehyde fixes tissue at a rate of 1 $\mathrm{mm} / \mathrm{h}$ [30]. Therefore, exposing 10- $\mu \mathrm{m}$-thick cryostat sections in 4\% FA for $15 \mathrm{~min}$ at room temperature is adequate to preserve antigenicity as well as morphology.

\subsubsection{Immunofluorescence staining}

Double staining is a challenge for cryostat sections. Tissue loss has been a concern in cryostat sections during 3-day procedures [11]. A shortened incubation time at room temperature with high concentrations of antibody has been suggested. However, using high concentrations of antibodies is expensive, and room temperature incubation for a brief period of time may reduce immunoreactivity [28]. In the present study cryostat sections fixed with $4 \%$ buffered formaldehyde were adequate for 3-day double staining procedures. It is important to notice that (1) cryostat sections must be mounted on superfrost plus microscope slides, and (2) before fixation, the sections must be dried out. It usually takes 30-60 $\mathrm{min}$ in room temperature. Prolonged drying is not recommended because of potential loss of immunoreactivity.

Four percent FA in PBS ( $\mathrm{pH}$ 7.4), and using PBS as working solution shows the same results as TBS.

\section{Quick procedure}

1. Transplant human bone marrow stem cells into rat brain.

2. Fast freeze brains on powdered dry ice. Store brains at $-80^{\circ} \mathrm{C}$. Cut cryostat sections (10- $\mu \mathrm{m}$-thick) and mount on superfrost slides. Store sections at $-80^{\circ} \mathrm{C}$. Dry out sections before staining.

3. Fix sections with $4 \%$ FA in buffered solution.

4. Expose to $0.3 \% \mathrm{H}_{2} \mathrm{O}_{2}$ to quench endogenous peroxidase activities. Block nonspecific binding with 
normal serum (diluted with $0.1 \% \mathrm{BSA}+0.25 \%$ Triton $\mathrm{X}-100$ ) from the species in which the secondary antibody was raised. Incubate with primary antibody at $4{ }^{\circ} \mathrm{C}$ overnight. Incubate with secondary antibody. Visualize immunoreactivity with either DAB or fluorescent dye.

\section{Essential literature references}

Refs. [2,6,10,11,16,19-21,25,35].

\section{Acknowledgements}

The authors wish to thank William F. Kaemmerer and Michael McPhee for help with the graphics, Dirk Keene for expanding hMAPCs, Zhenhong Nan for sectioning the neonatal brain and Kirstin Olmon for her administrative assistance. This work was supported by the Lyle French Neurosurgery Research Fund, the Ben and Beryl Miller Fund, the Cornford Endowment Fund, Supporters' United for Parkinson's Education and Research (SUPER) Fund, the Dorothy Cavine Endowment, the Elmer Isakson Parkinson's Disease Fund, the Children's Cancer Research Fund, University of Minnesota Bone Marrow Transplant Research Fund, the Leukemia Society of America 1F31AI/ GM10291 and NIH grants 1F30MH12157, RO1-HL69137, and RO1-NS40831.

\section{References}

[1] B. Baker-Cairns, K. Meyers, R. Hamilton, C. Smith, C. Tornatore, Immunohistochemical staining of fixed tissue using antigen retrieval and a thermal cycler, Biotechniques 20 (1996) 641-650.

[2] H. Battifora, Assessment of antigen damage in immunohistochemistry. The vimentin internal control, Am. J. Clin. Pathol. 96 (1991) 669-671.

[3] J.N. Beresford, J.H. Bennett, C. Devlin, P.S. Leboy, M.E. Owen, Evidence for an inverse relationship between the differentiation of adipocytic and osteogenic cells in rat marrow stromal cell cultures, J. Cell Sci. 102 (1992) 341-351.

[4] M.E. Boon, L.P. Kok, Microwaves for immunohistochemistry, Micron 25 (1994) 151-170.

[5] B. Bowers, M. Maser, Artifacts in fixation for transmission electron microscopy, in: R.F.E. Crang, K.L. Klomparens (Eds.), Artifacts in Biological Electron Microscopy, Plenum, New York, 1988, pp. $13-42$.

[6] T.R. Brazelton, F.M. Rossi, G.I. Keshet, H.M. Blau, From marrow to brain: expression of neuronal phenotypes in adult mice, Science 290 (2000) 1775-1779.

[7] P. Coyle, Middle cerebral artery occlusion in the young rat, Stroke 13 (1982) 855-859.

[8] R.C. Curran, J. Gregory, Demonstration of immunoglobulin in cryostat and paraffin sections of human tonsil by immunofluorescence and immunoperoxidase techniques. Effects of processing on immunohistochemical performance of tissues and on the use of proteolytic enzymes to unmask antigens in sections, J. Clin. Pathol. 31 (1978) 974-983.
[9] J.E. Dennis, S.E. Haynesworth, R.G. Young, A.I. Caplan, Osteogenesis in marrow-derived mesenchymal cell porous ceramic composites transplanted subcutaneously: effect of fibronectin and laminin on cell retention and rate of osteogenic expression, Cell Transplant. 1 (1992) 23-32.

[10] M.A. Eglitis, E. Mezey, Hematopoietic cells differentiate into both microglia and macroglia in the brains of adult mice, Proc. Natl. Acad. Sci. USA 94 (1997) 4080-4085.

[11] A.J. Farmilo, R.H. Stead, Fixation in immunocytochemistry, in: S.J. Naish (Ed.), Immunochemical Staining Methods, DAKO, Carpinteria, 1989, pp. 24-29.

[12] C.H. Fox, F.B. Johnson, J. Whiting, P.P. Roller, Formaldehyde fixation, J. Histochem. Cytochem. 33 (1985) 845-853.

[13] D.F. Horrobin, Lipid metabolism, human evolution and schizophrenia, Prostaglandins Leukot. Essent. Fatty Acids 60 (1999) 431-437.

[14] S.N. Huang, H. Minassian, J.D. More, Application of immunofluorescent staining on paraffin sections improved by trypsin digestion, Lab. Invest. 35 (1976) 383-390.

[15] A. Jassim, AJ-FS9 monoclonal antibody detects masked antigens with the human sperm tail fibrous sheath, Hum. Reprod. 9 (1994) $1836-1844$.

[16] Y. Jiang, B.N. Jahagirdar, R.L. Reinhardt, R.E. Schwartz, C.D. Keene, X.R. Ortiz-Gonzalez, M. Reyes, T. Lenvik, T. Lund, M. Blackstad, J. Du, S. Aldrich, A. Lisberg, W.C. Low, D.A. Largaespada, C.M. Verfaillie, Pluripotency of mesenchymal stem cells derived from adult marrow, Nature 418 (2002) 41-49.

[17] A.E. Kingsbury, E.L. Bray, O.J. Foster, A simplified and rapid procedure for in situ hybridization on human, flash-frozen, postmortem brain and its combination with immunohistochemistry, J. Neurosci. Methods 69 (1996) 213-227.

[18] Z. Kokaia, M. Metsis, M. Kokaia, J. Bengzon, E. Elmer, M.L. Smith, T. Timmusk, B.K. Siesjo, H. Persson, O. Lindvall, Brain insults in rats induce increased expression of the BDNF gene through differential use of multiple promoters, Eur. J. Neurosci. 6 (1994) 587-596.

[19] G.C. Kopen, D.J. Prockop, D.G. Phinney, Marrow stromal cells migrate throughout forebrain and cerebellum, and they differentiate into astrocytes after injection into neonatal mouse brains, Proc. Natl. Acad. Sci. USA 96 (1999) 10711-10716.

[20] M.A. Melan, Overview of cell fixation and permeabilization, Methods Mol. Biol. 34 (1994) 55-66.

[21] E. Mezey, K.J. Chandross, G. Harta, R.A. Maki, S.R. McKercher, Turning blood into brain: cells bearing neuronal antigens generated in vivo from bone marrow, Science 290 (2000) 1779-1782.

[22] R.J. Morris, P.C. Barber, Fixation of Thy-1 in nervous tissue for immunohistochemistry: a quantitative assessment of the effect of different fixation conditions upon retention of antigenicity and the cross-linking of Thy-1, J. Histochem. Cytochem. 31 (1983) 263274.

[23] J.D. Myers, Development and application of immunocytochemical staining techniques: a review, Diagn. Cytopathol. 5 (1989) 318-330.

[24] G. Nicolas, Advantages of fast-freeze fixation followed by freezesubstitution for the preservation of cell integrity, J. Electron Microsc. Tech. 18 (1991) 395-405.

[25] R.F. Pereira, K.W. Halford, M.D. O'Hara, D.B. Leeper, B.P. Sokolov, M.D. Pollard, O. Bagasra, D.J. Prockop, Cultured adherent cells from marrow can serve as long-lasting precursor cells for bone, cartilage, and lung in irradiated mice, Proc. Natl. Acad. Sci. USA 92 (1995) 4857-4861.

[26] R.F. Pereira, M.D. O’Hara, A.V. Laptev, K.W. Halford, M.D. Pollard, R. Class, D. Simon, K. Livezey, D.J. Prockop, Marrow stromal cells as a source of progenitor cells for nonhematopoietic tissues in transgenic mice with a phenotype of osteogenesis imperfecta, Proc. Natl. Acad. Sci. USA 95 (1998) 1142-1147.

[27] B.E. Petersen, W.C. Bowen, K.D. Patrene, W.M. Mars, A.K. Sullivan, N. Murase, S.S. Boggs, J.S. Greenberger, J.P. Goff, Bone marrow as a potential source of hepatic oval cells, Science 284 (1999) 1168-1170. 
[28] D.V. Pow, L.L. Wright, D.I. Vaney, The immunocytochemical detection of amino-acid neurotransmitters in paraformaldehyde-fixed tissues, J. Neurosci. Methods 56 (1995) 115-123.

[29] B.M. Riederer, R. Porchet, R.A. Marugg, L.I. Binder, Solubility of cytoskeletal proteins in immunohistochemistry and the influence of fixation, J. Histochem. Cytochem. 41 (1993) 609-616.

[30] O.J. Rustad, V. Kaye, R. Cerio, C.B. Zachary, Postfixation of cryostat sections improves tumor definition in Mohs surgery, J. Dermatol. Surg. Oncol. 15 (1989) 1262-1267.

[31] J. Sanchez-Ramos, S. Song, F. Cardozo-Pelaez, C. Hazzi, T. Stedeford, A. Willing, T.B. Freeman, S. Saporta, W. Janssen, N. Patel, D.R. Cooper, P.R. Sanberg, Adult bone marrow stromal cells differentiate into neural cells in vitro, Exp. Neurol. 164 (2000) 247-256.

[32] E. Scanziani, Immunohistochemical staining of fixed tissues, Methods Mol. Biol. 104 (1998) 133-140.

[33] S.R. Shi, M.E. Key, K.L. Kalra, Antigen retrieval in formalin-fixed, paraffin-embedded tissues: an enhancement method for immunohistochemical staining based on microwave oven heating of tissue sections, J. Histochem. Cytochem. 39 (1991) 741-748.
[34] S. Wakitani, T. Saito, A.I. Caplan, Myogenic cells derived from rat bone marrow mesenchymal stem cells exposed to 5-azacytidine, Muscle Nerve 18 (1995) 1417-1426.

[35] M. Werner, R. Von Wasielewski, P. Komminoth, Antigen retrieval, signal amplification and intensification in immunohistochemistry, Histochem. Cell. Biol. 105 (1996) 253-260.

[36] D. Woodbury, E.J. Schwarz, D.J. Prockop, I.B. Black, Adult rat and human bone marrow stromal cells differentiate into neurons, J. Neurosci. Res. 61 (2000) 364-370.

[37] L.R. Zhao, W.M. Duan, M. Reyes, C.D. Keene, C.M. Verfaillie, W.C. Low, Human bone marrow stem cells exhibit neural phenotypes and ameliorate neurological deficits after grafting into the ischemic brain of rats, Exp. Neurol. 174 (2002) 11-20.

[38] L.R. Zhao, B. Mattsson, B.B. Johansson, Environmental influence on brain-derived neurotrophic factor messenger RNA expression after middle cerebral artery occlusion in spontaneously hypertensive rats, Neuroscience 97 (2000) 177-184. 